\title{
Local Hemodynamics of the Vascular Access for Hemodialysis
}

\author{
$\begin{array}{lll}\text { J. Malik } & \text { V. Tuka } & \text { V. Tesar } \\ & & \end{array}$ \\ aThird Department of Internal Medicine and bepartment of Nephrology, General University Hospital, \\ First School of Medicine, Charles University, Prague, Czech Republic
}

\section{Key Words}

Vascular access $\cdot$ Hemodialysis $\cdot$ Wall shear stress

\begin{abstract}
Vascular access is called Achilles' heel of hemodialysis because it is associated with a substantial morbidity. A permanent vascular access is created either by a direct connection of the patient's own artery and vein or by the interposition of a graft. Arteriolar beds are bypassed, which leads to a substantial increase in arterial (and venous) flow and the vessels adapt to it by a complex of interesting processes. These are reviewed together with some pathophysiological mechanisms of access complications.
\end{abstract}

Copyright $\odot 2009$ S. Karger AG, Basel

\section{Introduction}

Most end-stage renal disease (ESRD) patients are treated with hemodialysis. Such therapy needs regular entries into the blood stream, usually 2-3 times/week. Although a permanent venous catheter could be used for this purpose, its use is associated with increased morbidity and mortality due to infections $[1,2]$. Therefore, a permanent vascular access (also called 'shunt') is preferred. Such access bypasses the arteriolar beds, which leads to a substantial flow increase and some interesting adaptation processes.

\section{KARGER \\ Fax +41613061234 E-Mail karger@karger.ch} www.karger.com
Vascular accesses are called 'lifelines' for patients on hemodialysis. Unfortunately, the life span of these patients is limited [3] and their management is associated with significant morbidity and costs $[4,5]$. Understanding the mechanisms of access maturation and of the development of complications is necessary for proper access management. From the clinical point of view, a good vascular access should: (1) provide adequate blood flow for the hemodialysis (>300-500 $\mathrm{ml} / \mathrm{min}$ ); (2) have a superficial position - to be easily cannulated for dialysis; (3) have a long life span, and (4) no or a low complication rate [6].

We review the interesting hemodynamic, biochemical and clinical aspects of vascular accesses, which are overviewed in table 1.

\section{Physiological Changes after Access Creation}

The native vascular access (arteriovenous fistula, AVF) is created by the direct connection of the patient's own vein and artery. Usually an end-of-vein to side-of-artery technique is used. The most common types include radiocephalic and brachiocephalic fistulas. When patent straight superficial veins are lacking, a polytetrafluoro-

The authors are supported by the grant No. 8334/4 from the Internal Grant Agency, Ministry of Health, Czech Republic.

Jan Malik, MD, PhD

Third Department of Internal Medicine

General University Hospital, U nemocnice 1

CZ-12808 Prague (Czech Republic)

Tel./Fax +420 224923 852, E-Mail malik.jan@vfn.cz 
Table 1. Overview of factors leading to access dysfunction

\begin{tabular}{lll}
\hline Site & Mechanism & Complication \\
\hline Feeding artery & $\begin{array}{l}\text { Endothelial dysfunction/atherosclerosis } \\
\text { Medial calcinosis }\end{array}$ & $\begin{array}{l}\text { Inadequate flow/maturation } \\
\text { Hand ischemia }\end{array}$ \\
\hline Arterial anastomosis & Wide & High-flow access \\
& Narrow & Low-flow access \\
& Blood jet against venous wall & Venous aneurysm/stenosis \\
\hline Venous anastomosis of PTFE & Mismatch in elastic wall properties & Neointimal hyperplasia/stenosis \\
& Wall shear stress changes & \\
& Geometry of the adjacent vein & \\
\hline Outflow vein & Jet from the anastomosis & Aneurysm/stenosis \\
& Puncture technique & \\
\hline Dialysis needles & Fast blood jet & Platelet activation \\
& & Neointimal hyperplasia? \\
\hline
\end{tabular}

ethylene (PTFE) graft is used as a bridge between an artery and a superficial or deep vein; this graft is punctured during hemodialysis. Other access types are less common and include native or PTFE accesses in lower extremities, allografts, PTFE grafts at the patient's trunk, etc. $[1,7]$.

Just after vascular access creation, the resistant arterioles are bypassed, which leads to a sudden decrease in peripheral vascular resistance (PVR) and to a substantial increase in access flow (through the feeding artery, graft and outflow vein). While brachial artery flow is $60-120$ $\mathrm{ml} / \mathrm{min}$ in healthy resting individuals and even less in ERSD patients (own unpublished data), it reaches 500$2,000 \mathrm{ml} / \mathrm{min}$ in the extremity with an access. Obviously, such an increase in flow volume must lead to both local (arterial and venous) and systemic changes.

\section{Feeding Artery}

Arterial endothelial cells sense the sudden increase in arterial flow which occurs just after access creation. The endothelium responds by the increased bioavailability of nitric oxide (NO), which is the strongest endogenous arterio-dilating agent [8]. This is why this mechanism is used to test the flow-mediated dilation of the brachial artery after temporary forearm ischemia; the level of dilatation corresponds to endothelial (dys)function [9]. Physiologically, blood flow acceleration with a diameter increase occurs during physical training. The physiological purpose of the arterio-dilatation in response to the blood flow increase is to enable perfusion of working muscles, to heal local inflammation, etc., by a decrease in PVR [10] because flow volume is directly related to cardiac output and indirectly to PVR. Naturally, the dilatation of small arterioles is mathematically and physiologically more significant for limb perfusion than dilatation of the proximal arteries.

From the hemodynamic point of view, the effect of blood on the arterial wall could be described by pressure and flow. The pressure acts perpendicularly on the arterial wall and is therefore sensed by all wall layers. This leads to wall strain, expressed by the law of Laplace. A detailed description of the blood pressure effect on the arterial wall is beyond the scope of this review [for details see 11].

Unlike blood pressure, blood flow acts only on the inner surface of the arterial wall and thus directly affects only endothelial cells and not the medial and adventitial layers. Wall shear stress (WSS) is the mathematical description of the blood flow effect on the endothelium [12, 13]. It is a force that is mathematically expressed as a vector, with direction and magnitude. The direction corresponds to the blood flow direction and its magnitude is directly proportional to wall shear rate (WSR) and blood viscosity $[12,14,15]$ :

$$
\text { WSS }=\sigma \cdot \operatorname{WSR}(\mathrm{Pa}),
$$

where $\sigma$ is whole blood viscosity. WSR is defined as the difference between adjacent velocities in the vascular lumen divided by their distance. Because of technical limitations, centerline blood velocity and arterial radius are 
used as the approximation of WSR. As we can measure peak and mean blood velocity (e.g. by Doppler ultrasonography), we can also differentiate between peak and mean WSS - it is of particular importance in high-resistant flow. Pascal (Pa) is the official unit of WSS, but it is usually replaced by dynes per square centimeter.

In general, arterial adaptation is directed towards restoration of hemodynamic parameters to baseline physiological values $[10,16-19]$. An increase in blood flow velocity leads to a rise in WSS, which is restored by arterial dilatation: a negative feedback loop [20]. A decrease in PVR in the feeding artery differs from the reaction to physical training and to local inflammation by 2 factors: it is very profound and long-term. Others [21-23] and we $[24,25]$ have studied WSS in the feeding artery up to 2 years after access creation. It remained supra-physiologi$\mathrm{cal}$, mainly in accesses originating from the radial artery and in diabetics. Thus, the leading force of arterio-dilatation - WSS - remains high. Indeed, the feeding artery continues to dilate within the 2 nd year after access creation. On the contrary, in some animal models of AVFs, WSS normalized sooner. In an iliac AVF model in rats, WSS returned to its baseline values after 42 days [26]. Six months after the construction of an AVF between the right iliac artery and vein in monkeys, blood flow increased with a consequent twofold internal diameter increase and WSS remained unchanged [27]. Kamiya and Togawa [14] created a carotid artery to external jugular vein fistula to study the adaptation of the dog carotid artery to increased flow. They showed that the artery with high flow adapted completely by enlargement to reduce the WSS to physiological baseline values of 15 dynes $/ \mathrm{cm}^{2}$. Similar findings were reported by Zarins et al. [27] in a hypercholesterolemic monkey model. But the question remains: why does WSS not normalize in the human dialysis access feeding artery? We can hypothesize that (1) it takes even more time than 2 years; (2) it is due to a complex of differences in vascular physiology between human beings and animals, and (3) it is due to pathological changes associated with both ESRD and comorbidities.

Arterial dilatation in response to blood flow acceleration after access creation is mediated by NO. However, it is known that acute arterio-dilatation is limited (it could be tested by direct application of NO donors, such as nitroglycerine). On the other hand, arterial dilatation in response to chronically high blood flow continues further behind these limits. It is due to morphological changes in the arterial wall, including degradation or fenestration of the basal membrane by matrix metalloproteinases. Tronc et al. [28] documented that the matrix metalloproteinases are directly activated by NO. Therefore, NO plays a pivotal role in both acute and chronic dilatation of the access feeding artery. As the endothelium is the only endogenous source of this molecule, endothelial dysfunction contributes to limited feeding artery dilatation. Endothelial dysfunction is associated with dyslipidemia, hypertension, diabetes mellitus, uremia, etc. [29-31]. In our previous study we observed slower long-term arterial dilatation in patients with diabetes mellitus and elevated serum cholesterol levels [24]. Of course, the magnitude of vasodilatation is also negatively related to the degree of vessel wall calcification [32, 33], which is more pronounced in diabetic patients and known as mediocalcinosis [34]. It has been documented that endothelial cells sense steady and pulsatile shear stress differently [15]. The increase in mean and peak WSS after vascular access creation is not proportional: whereas mean WSS increases 4- to 6-fold, peak WSS increases only little [21-23]. It is especially due to the change in the diastolic flow pattern from high-resistant (near-tozero diastolic flow) to low-resistant (orthograde flow during the whole cardiac cycle). After 1 year, the vasodilatation continues with persistently increased mean and peak WSS $[22,23]$. Therefore, it seems that it is the peak (and not mean) WSS, which plays the main role in the arterial diameter changes directed to maintain the WSS constant [21]. In other words, the oscillatory WSS is sensed rather than mean WSS by the endothelium [23].

As a result of atherosclerosis and/or medial calcinosis, arterial stenosis could develop at any part of the extremity with vascular access. While medial calcinosis affects especially distal parts of the arterial tree, atherosclerotic plaques are predominantly located along the outer walls of bifurcations. Hemodynamically significant stenoses located proximal to the arterial anastomosis usually lead to a decrease in access flow. Hand ischemia could develop in the case of both proximal or distal arterial stenoses [35].

\section{Arterial Anastomosis}

Arterial anastomosis is the site, where the high-pressure feeding artery is connected to the low-pressure graft or native vein. Arterial anastomosis of native accesses probably plays a role in outflow vein stenosis. While in the past the side-to-side technique was sometimes used, now the preferred method is end (of vein or graft)-to-side (of the artery) [36]. The venous segment perpendicular to the artery is usually very short due to the skin cover and 
due to vein fixation to surrounding tissues. Therefore, the anastomosis produces a jet of blood flow along the venous wall. Then the blood stream is turned along the outer venous wall so that some sites are exposed to low and others to high WSS. This could lead to the development of venous aneurysms, which are, sometimes, followed by stenosis. Indeed, the vast majority of native access stenoses are located within a few centimeters of the arterial anastomosis $[37,38]$.

\section{Blood Flow}

Generally, arterial flow is directly related to the perfusion pressure and indirectly to PVR. This mechanism is maintained in conduit arteries which supply the tissues of the extremity with access. The blood flow volume through an arteriovenous access (conduit) is related to the diameter of the fistula and anastomosis and the inflow artery. In small arteriovenous conduits, where the fistula diameter is less than $3 / 4$ of the inflow artery, the flow is regulated mainly by the fourth power of the fistula radius. In large arteriovenous conduits, where the diameter of the anastomosis and outflow circuit is equal or greater than that of the donor artery, volume blood flow is regulated mainly by the summary resistances of the peripheral vascular bed, the donor artery and the collateral circulation, similar to that of an electric model consisting of high- and low-resistance circuits $[39,40]$. Perfusion pressure is generated by the left ventricle and is augmented by pressure wave reflections [41]. Perfusion pressure drops in significant arterial stenoses.

Blood flow volumes are usually lower in distal accesses, i.e. originating from the radial artery. They range from $300-700 \mathrm{ml} / \mathrm{min}$ in native radiocephalic fistulas to $500-1,000 \mathrm{ml} / \mathrm{min}$ in distal grafts. Usual values of flow volume in accesses with the arterial anastomosis on the brachial artery are $700-1,500 \mathrm{ml} / \mathrm{min}$ [42]. So-called high-flow access is that with a flow volume of $>1,800$ $2,000 \mathrm{ml} / \mathrm{min}$. These values become optically higher if we compare them with the normal resting cardiac output (4-6 l/min). High-access flow could lead to heart failure (congestive or hyperkinetic) and sometimes to hand ischemia [35].

Case reports of hyperkinetic heart failure as a result of high-flow access have been published, such as that of Jin et al. [43]. More commonly, access flow contributes to the development of already present congestive heart failure either clinically silent or overt.
It has been documented that access creation leads to some significant systemic changes - to dilatation of the left ventricle, decrease in systemic blood pressure, heart rate acceleration, and increased brain natriuretic peptide, etc. [44-46]. To simplify, vascular access flow has a hemodynamic effect similar to anemia and water retention. The authors of the studies, however, usually did not measure the access flow, which makes this topic even more complicated. Moreover, these studies were limited to as little as a few months. Unfortunately, it is difficult to perform a longer study with the exclusion of potential confounding variables (such as comorbidities, progression of kidney failure), because such variables also change over time. Chemla et al. [47] documented relief of heart failure symptoms and decrease in cardiac output after surgical high-access flow reduction. Interestingly, it seems that the necessary increase in cardiac output to sustain the high-access flow must be numerically greater than the actual access flow [48].

Surprisingly, many patients tolerate high-access flow quite well. Nevertheless, we recommend examinations of the patients by echocardiography every 6-12 months to avoid pathological dilatation of the left ventricle. Patients should also be asked if they have symptoms of heart failure or hand ischemia, and brain natriuretic peptide levels should be checked.

In the clinical routine, access flow is measured by dilution techniques, such as thermodilution, ultrasound dilution or by duplex Doppler ultrasonography [49]. It is advisable to obtain reproducibility data in all hemodialysis units.

Forearm accesses are fed by both forearm arteries e.g., radiocephalic fistula also receives blood from the ulnar artery via palmar arch. The retrograde flow in the radial artery distal to the anastomosis can easily be documented by ultrasonography and occurs in more than $99 \%$ of all forearm accesses. This is a steal phenomenon with no clinical relevance in the vast majority of patients. Ligation of the distal part of the radial artery is indicated only in some special situations of hand ischemia [50].

\section{Outflow Vein}

The normal venous wall is considerably thinner than the arterial one. After access creation, it thickens in a process sometimes called 'arterialization'. It seems that the diameter of the outflow vein also depends on some systemic variables because various causes of ESRD are associated with different venous diameters [51]. Enormous 

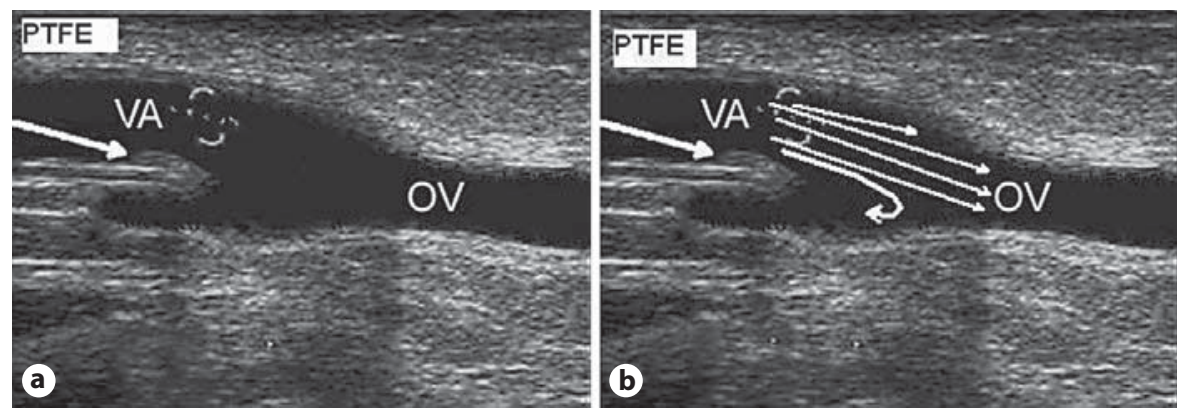

Fig. 1. Venous anastomosis of a PTFE vascular access. The connection of the PTFE graft to the outflow vein $(\mathrm{OV})$ is shown in B-mode ultrasonography, longitudinal section. a The proximal end of the graft (venous anastomosis, VA) is frequently affected by neointimal hyperplasia (arrow). Neointimal hyperplasia could, however, occur also in the adjacent part of the outflow vein. $\mathbf{b}$ The flow velocity and vector (respectively wall shear stress) play a role in the development of venous neointimal hyperplasia and steno- sis. Some venous segments are exposed to very high blood velocity, which could desquamate endothelial cells and activate thrombogenic factors, such as von Willebrand factor. Other segments are exposed to slow blood flow with varying vectors. Such areas are known by the frequent development of atherosclerosis plaques in the arterial tree and probably also predispose to the development of neointimal hyperplasia. The flow characteristics depend on VA geometry. dilatation (aneurysms) develops in some patients. The puncture technique plays a substantial role in the development of aneurysms [52, 53]. Basically, 3 methods of access cannulation are used: (1) rope ladder cannulation (changing the puncture sites along the access); (2) area puncture cannulation (punctures within a short access segment), and (3) buttonhole technique (punctures into exactly the same sites). Area punctures are most often associated with aneurysms, buttonhole technique least.

Stenoses of outflow veins usually develop close to the arterial anastomosis (see above). Some patients have central vein stenoses as a result of previously used central vein catheters.

\section{Venous Anastomosis of PTFE Grafts}

Venous anastomosis is the site where the graft is connected to the patient's own vein. It is of particular clinical importance because the majority of access stenoses develop here. They affect either the site of the graft-vein connection (venous anastomosis per se) or the adjacent part of the outflow vein. From a practical point of view, it should be mentioned that it is easy to distinguish the graft and venous wall by ultrasonography, but it is harder to do this by angiography because only filling of the vessels by a contrast agent could be seen.

Neointimal hyperplasia $(\mathrm{NH})$ is responsible for the development of stenoses at the venous anastomosis. At a histological level, $\mathrm{NH}$ is characterized by smooth muscle cell/myofibroblast proliferation, angiogenesis (microvessel formation), and matrix deposition [54]. This is a mechanism similar to restenosis formation after balloon angioplasty of the coronary and peripheral arteries and to $\mathrm{NH}$ formation in PTFE arterio-arterial grafts. However, $\mathrm{NH}$ in the setting of dialysis access is a far more aggressive lesion [54].

A number of studies have tried to investigate the reasons of $\mathrm{NH}$ formation.

(1) Mechanical and hemodynamic factors. Suture of the PTFE graft to the patient's vein leads to microtrauma of the venous wall, the healing of which could be the first signal for NH development. The wall of the PTFE graft has considerably different elastic properties than the natural venous wall. A mismatch in elastic properties was suggested as a cause of $\mathrm{NH}$ by Hofstra et al. [55]. Later research was oriented to the role of WSS in NH formation. Blood is jetted from the venous anastomosis against the floor of the outer vein wall. See figure 1 for an explanation. During the months after access creation, the outflow vein dilates and its wall thickens, while the lumen of the graft in the anastomosis remains constant or even smaller due to $\mathrm{NH}$. Venous dilatation predisposes to the development of flow reversal sites (along the inner venous wall). As a result, sites with slow blood flow (and low WSS) along the venous wall develop. High blood pressure in the outflow vein prevents venous constriction in response to the WSS decrease. Sites with chronically low WSS are predisposed to the development of atherosclerotic plaques in the arterial tree and a similar effect plays 
a role in the development of NH. Such effects could be studied by simulations of fluid dynamics $[56,57]$. The findings of these studies stimulated the development of a vascular graft with a preformed cuff shape at the venous end to reduce the area of flow reversal.

However, as the NH develops to a significant stenosis, there is blood flow acceleration with an increase in WSS. High WSS leads to endothelial desquamation and to increased synthesis of VEGFR-1, VEGFR-2 and matrix metalloproteinase-2.

(2) Humoral and cellular stimuli. The PTFE graft functions as a foreign body. Indeed, the highest risk of graft thrombosis is in newer grafts prior to complete endothelialization [58]. Uremia per se and especially its frequent causes - diabetes and hypertension - are risk factors of endothelial dysfunction which could predispose to $\mathrm{NH}$. As a response to the hemodynamic effects, activation of the endothelium and smooth muscle cells in the vascular intima and media develops. Smooth muscle cells and myofibroblasts migrate from the media to the intima, resulting in the formation of $\mathrm{NH}$. A plethora of cytokines and inflammatory mediators have been implicated in these processes. They include intercellular adhesive molecule-I [59], P-selectin [60], osteopontin [61], matrix metalloproteinase-2 [62], hypoxia-inducible factor- $1 \alpha$, etc. [54]. The molecular interactions involved in the pathogenesis of vascular access complications are intriguingly reviewed by Diskin et al. [63].

\section{Hemodynamics of the Dialysis Needles}

ESRD patients usually spend 3-5 hours three times/ week on hemodialysis with 1-2 needles inserted into their access. The needles influence the hemodynamics of the access in different manners: (1) microtrauma of the puncture, and (2) changes in access blood flow velocity and pattern.

The 'inflow' needle takes the blood from the patient to the dialysis machine and the 'outflow' needle transports it back to the vascular access. Suction of the blood by the inflow needle causes a turbulent flow around this needle. Furthermore, in low-flow accesses, the majority of the access flow is removed by the inflow needle, which results in a temporary (intradialytic) decrease in blood flow velocity in the access segment between the needles. Such a decrease in blood velocity could predispose to the hypercoagulable state and to a decrease in WSS with a possible impact on NH development (see above). The outflow needle jets the blood stream against the access wall.
In in vitro models, where the needle was oriented parallel to the long axis of the PTFE graft, the velocity at the orifice is $350 \mathrm{~cm} / \mathrm{s}$ at the tip of the needle with a needle flow of $300 \mathrm{ml} / \mathrm{min}$ and reaches a velocity of $80 \mathrm{~cm} / \mathrm{s} 6 \mathrm{~cm}$ downstream, which approaches the velocity of normal graft flow without the needle inserted [64]. However, the needle usually does not have a parallel orientation and is oriented towards one access wall [65]. The high-velocity flow jet 'hurts' the wall. This leads to endothelial denudation and, potentially, to decreased NO production [66].

It has been suggested that the flow jet is a related factor towards the development of NH [54, 64]. Downstream of the 'outflow' needle, where the flow jet entrains the particles of the 'normal' flow in the vascular access, it creates a region of flow instability and turbulence. At the jet boundary regions, high-shearing forces can be observed [64] and direct platelet activation occurs under high WSR [67]. The platelets produce PDGF and other cytokines that create a proinflammatory milieu downstream at the venous anastomosis [54]. Von Willebrand factor is also activated in high WSS and contributes to the development of fibrin-platelet thrombi on PTFE surfaces. Fibrin deposition increases with rising shear rate in the presence of von Willebrand factor [68]. Thus the needle jet creates conditions for the formation of thrombi and intimal hyperplasia. We should stress that there are still very little data on the real impact of the needles on vascular access complications.

\section{Conclusions}

Creation of a permanent vascular access and its maturation leads to a complex of physiological hemodynamic changes. Extreme flow acceleration could induce endothelial denudation, activation of thrombogenic factors and cytoadhesive molecules in some sites. These factors, together with the non-physiological milieu of ESRD, contribute to the development of access complications. 


\section{References}

1 Tordoir J, Canaud B, Haage P, Konner K, Basci A, Fouque D, Kooman J, Martin-Malo A, Pedrini L, Pizzarelli F, Tattersall J, Vennegoor M, Wanner C, ter Wee P, Vanholder R: EBPG on vascular access. Nephrol Dial Transplant 2007;22(suppl 2):ii88-ii117.

-2 Dhingra RK, Young EW, Hulbert-Shearon TE, Leavey SF, Port FK: Type of vascular access and mortality in US hemodialysis patients. Kidney Int 2001;60:1443-1451.

$\checkmark 3$ Cernadas MR, Grandjean M, Tosi MA: Vascular access patency and complications: a comparison of brachiobasilic AV fistulas and PTFE brachioaxillary bridge AV fistulas in hemodialysis patients. Dial Transplant 2003;32:694-697.

4 Tordoir JH, Van Der Sande FM, De Haan MW: Current topics on vascular access for hemodialysis. Minerva Urol Nefrol 2004;56: 223-235.

$\checkmark 5$ Dumars MC, Thompson WE, Bluth EI, Lindberg JS, Yoselevitz M, Merritt CR: Management of suspected hemodialysis graft dysfunction: usefulness of diagnostic US. Radiology 2002;222:103-107.

-6 Thalhammer C, Aschwanden M, Staub D, Dickenmann M, Jaeger KA: Duplex sonography of hemodialysis access. Ultraschall Med 2007;28:450-471.

7 Vascular Access 2006 Work Group: Clinical practice guidelines for vascular access. Am J Kidney Dis 2006;48(suppl 1):S176-S247.

8 Furchgott RF, Zawadzki JV: The obligatory role of endothelial cells in the relaxation of arterial smooth muscle by acetylcholine. $\mathrm{Na}$ ture 1980;288:373-376.

9 Celermajer DS, Sorensen KE, Bull C, Robinson J, Deanfield JE: Endothelium-dependent dilation in the systemic arteries of asymptomatic subjects relates to coronary risk factors and their interaction. J Am Coll Cardiol 1994;24:1468-1474.

-10 Zakrzewicz A, Secomb TW, Pries AR: Angioadaptation: keeping the vascular system in shape. News Physiol Sci 2002;17:197-201.

-11 London GM, Marchais SJ, Guerin AP: Arterial stiffness and function in end-stage renal disease. Adv Chronic Kidney Dis 2004;11: 202-209.

12 Paszkowiak JJ, Dardik A: Arterial wall shear stress: observations from the bench to the bedside. Vasc Endovascular Surg 2003;37: 47-57.

13 Rotreklova J, Molinsky J, Tuka V, Malik J: Wall shear stress and endothelium (in Czech). Cas Lek Cesk 2004;143:467-470.

14 Kamiya A, Togawa T: Adaptive regulation of wall shear stress to flow change in the canine carotid artery. Am J Physiol Heart Circ Physiol 1980;239:H14-H21.

-15 Malek AM, Alper SL, Izumo S: Hemodynamic shear stress and its role in atherosclerosis. JAMA 1999;282:2035-2042.
16 Kamiya A, Bukhari R, Togawa T: Adaptive regulation of wall shear stress optimizing vascular tree function. Bull Math Biol 1984; 46:127-137.

17 Kassab GS, Fung YC: The pattern of coronary arteriolar bifurcations and the uniform shear hypothesis. Ann Biomed Eng 1995;23: 13-20.

-18 Samijo SK, Willigers JM, Barkhuysen R, Kitslaar PJEHM, Reneman RS, Brands PJ, Hoeks APG: Wall shear stress in the human common carotid artery as function of age and gender. Cardiovasc Res 1998;39:515522.

19 Wu SP, Ringgaard S, Oyre S, Hansen MS, Rasmus S, Pedersen EM: Wall shear rates differ between the normal carotid, femoral, and brachial arteries: an in vivo MRI study. J Magn Reson Imaging 2004;19:188-193.

20 Tedgui A, Lehoux S, Levy BI: Mechanical factors and vascular biology; in Levy BI, Tedgui A (eds): Biology of the Arterial Wall. Dordrecht, Kluwer Academic, 1999.

-21 Ene-Iordache B, Mosconi L, Antiga L, Bruno S, Anghileri A, Remuzzi G, Remuzzi A: Radial artery remodeling in response to shear stress increase within arteriovenous fistula for hemodialysis access. Endothelium 2003 10:95-102.

22 Dammers R, Tordoir JH, Kooman JP, Welten RJ, Hameleers JM, Kitslaar PJ, Hoeks AP The effect of flow changes on the arterial system proximal to an arteriovenous fistula for hemodialysis. Ultrasound Med Biol 2005;31: 1327-1333.

-23 Dammers R, Tordoir JHM, Welten RJ, Kitslaar PJEHM, Hoeks APG: The effect of chronic flow changes on brachial artery diameter and shear stress in arteriovenous fistulas for hemodialysis. Int J Artif Organs 2002;25:124-128.

24 Tuka V, Slavikova M, Kasalova Z, Malik J: Factors associated with impaired arterial adaptation to chronically high wall shear rate in the feeding artery of PTFE grafts. Am J Nephrol 2008;28:847-852.

25 Tuka V, Slavikova M, Svobodova J, Malik J: Diabetes and distal access location are associated with higher wall shear rate in feeding artery of PTFE grafts. Nephrol Dial Transplant 2006;67:1554-1558.

26 Guzman RJ, Abe K, Zarins CK: Flow-induced arterial enlargement is inhibited by suppression of nitric oxide synthase activity in vivo. Surgery 1997;122:273-280.

27 Zarins CK, Zatina MA, Giddens DP, Ku DN Glagov S: Shear stress regulation of artery lumen in experimental atherogenesis. J Vasc Surg 1987;5:413-420.

28 Tronc F, Mallat Z, Lehoux S, Wassef M, Esposito B, Tedgui A: Role of matrix metalloproteinases in blood flow-induced arterial enlargement: interaction with NO. Arterioscler Thromb Vasc Biol 2000;20:120-126.
29 Brunner H, Cockcroft JR, Deanfield J, Donald A, Ferrannini E, Halcox J, Kiowski W, Luscher TF, Mancia G, Natali A, Oliver JJ, Pessina AC, Rizzoni D, Rossi GP, Salvetti A, Spieker LE, Taddei S, Webb DJ: Endothelial function and dysfunction. Part II: Association with cardiovascular risk factors and diseases. A statement by the Working Group on Endothelins and Endothelial Factors of the European Society of Hypertension. J Hypertens 2005;23:233-246.

30 Meigs JB, Hu FB, Rifai N, Manson JE: Biomarkers of endothelial dysfunction and risk of type 2 diabetes mellitus. JAMA 2004;291: 1978-1986.

31 Schiffrin EL, Lipman ML, Mann JF: Chronic kidney disease: effects on the cardiovascular system. Circulation 2007;116:85-97.

32 Ishimura E, Okuno S, Taniwaki H, Kizu A, Tsuchida T, Shioi A, Shoji T, Tabata T, Inaba M, Nishizawa Y: Different risk factors for vascular calcification in end-stage renal disease between diabetics and nondiabetics: the respective importance of glycemic and phosphate control. Kidney Blood Press Res 2008; 31:10-15.

$>33$ Huang PH, Chen LC, Leu HB, Ding PA, Chen JW, Wu TC, Lin SJ: Enhanced coronary calcification determined by electron beam CT is strongly related to endothelial dysfunction in patients with suspected coronary artery disease. Chest 2005;128:810815.

34 Edmonds ME: Medial arterial calcification and diabetes mellitus. Z Kardiol 2000; 89(suppl 2):S101-S104.

\$5 Malik J, Tuka V, Kasalova Z, Chytilova E, Slavikova M, Clagett P, Davidson I, Dolmatch B, Nichols D, Gallieni M: Understanding the dialysis access steal syndrome. A review of the etiologies, diagnosis, prevention and treatment strategies. J Vasc Access 2008;9:155-167.

36 Konner K, Nonnast-Daniel B, Ritz E: The arteriovenous fistula. J Am Soc Nephrol 2003; 14:1669-1680.

37 Grogan J, Castilla M, Lozanski L, Griffin A, Loth F, Bassiouny H: Frequency of critical stenosis in primary arteriovenous fistulae before hemodialysis access: should duplex ultrasound surveillance be the standard of care? J Vasc Surg 2005;41:1000-1006.

-38 Sivanesan S, How TV, Bakran A: Sites of stenosis in AV fistulae for haemodialysis access. Nephrol Dial Transplant 1999;14:118-120.

39 Wixon CL, Hughes JD, Mills JL: Understanding strategies for the treatment of ischemic steal syndrome after hemodialysis access. J Am Coll Surg 2000;191:301-310.

40 Paulson WD, Jones SA: Hemodynamics of the hemodialysis access: implications for clinical management; in Ronco C, Levin NW (eds): Hemodialysis Vascular Access and Peritoneal Dialysis Access. Contrib Nephrol. Basel, Karger, 2004, vol 142, pp 238-253. 
41 Stancanelli B, Malatino LS, Malaponte G, Noto P, Giuffre E, Caruso A, Gagliano C, Zoccolo AM, Puccia G, Castellino P: Pulse pressure is an independent predictor of aortic stiffness in patients with mild to moderate chronic kidney disease. Kidney Blood Press Res 2007;30:283-288.

$\checkmark 42$ Chin AI, Chang W, Fitzgerald JT, Schanzer A, Perez RV, McVicar JP, Troppmann C: Intra-access blood flow in patients with newly created upper-arm arteriovenous native fistulae for hemodialysis access. Am J Kidney Dis 2004;44:850-858.

-43 Jin H, Afonso L, Singh A, Migdal S, Spears JR: Case report: recurrent heart failure with preserved ejection fraction but markedly elevated BNP in a 51-year-old female on hemodialysis with oversized AV fistula. Int J Cardiol 2006;110:429-430.

-44 Iwashima Y, Horio T, Takami Y, Inenaga T, Nishikimi T, Takishita S, Kawano Y: Effects of the creation of arteriovenous fistula for hemodialysis on cardiac function and natriuretic peptide levels in CRF. Am J Kidney Dis 2002;40:974-982.

-45 London GM, Guerin AP, Marchais SJ, Pannier B, Safar ME, Day M, Metivier F: Cardiac and arterial interactions in end-stage renal disease. Kidney Int 1996;50:600-608.

-46 Ori Y, Korzets A, Katz M, Perek Y, Zahavi I, Gafter U: Haemodialysis arteriovenous access - a prospective haemodynamic evaluation. Nephrol Dial Transplant 1996;11:9497.

-47 Chemla ES, Morsy M, Anderson L, Whitemore A: Inflow reduction by distalization of anastomosis treats efficiently high-inflow high-cardiac output vascular access for hemodialysis. Semin Dial 2007;20:68-72.

-48 Murray BM, Rajczak S, Herman A, Leary D: Effect of surgical banding of a high-flow fistula on access flow and cardiac output: intraoperative and long-term measurements. Am J Kidney Dis 2004;44:1090-1096.

49 Lopot F, Nejedly B, Sulkova S, Blaha J: Comparison of different techniques of hemodialysis vascular access flow evaluation. J Vasc Access 2004;5:25-32.
50 Miller GA, Khariton K, Kardos SV, Koh E, Goel N, Khariton A: Flow interruption of the distal radial artery: treatment for finger ischemia in a matured radiocephalic AVF. J Vasc Access 2008;9:58-63.

51 Hage FG, Smalheiser S, Zoghbi GJ, Perry GJ, Deierhoi M, Warnock D, Iskandrian AE, de Mattos AM, Aqel RA: Predictors of survival in patients with end-stage renal disease evaluated for kidney transplantation. Am J Cardiol 2007;100:1020-1025.

52 Murcutt G: Buttonhole cannulation: should this become the default technique for dialysis patients with native fistulas? Summary of the EDTNA/ERCA Journal Club discussion autumn 2007. J Ren Care 2008;34:101-108.

53 Verhallen AM, Kooistra MP, van Jaarsveld BC: Cannulating in haemodialysis: ropeladder or buttonhole technique? Nephrol Dial Transplant 2007;22:2601-2604.

54 Roy-Chaudhury P, Kelly BS, Zhang J, Narayana A, Desai P, Melhem M, Duncan H, Heffelfinger SC: Hemodialysis vascular access dysfunction: from pathophysiology to novel therapies. Blood Purif 2003;21:99-110.

55 Hofstra L, Bergmans DC, Hoeks AP, Kitslaar PJ, Leunissen KM, Tordoir JH: Mismatch in elastic properties around anastomoses of interposition grafts for hemodialysis access. J Am Soc Nephrol 1994;5:1243-1250.

56 Krueger U, Zanow J, Scholz H: Comparison of two different arteriovenous anastomotic forms by numerical 3D simulation of blood flow. Int J Angiol 2000;9:226-231.

57 Perktold K, Leuprecht A, Prosi M, Berk T, Czerny M, Trubel W, Schima H: Fluid dynamics, wall mechanics, and oxygen transfer in peripheral bypass anastomoses. Ann Biomed Eng 2002;30:447-460.

58 Ram SJ, Nassar R, Work J, Abreo K, Dossabhoy NR, Paulson WD: Risk of hemodialysis graft thrombosis: analysis of monthly flow surveillance. Am J Kidney Dis 2008;52:930938.

59 Zou Y, Hu Y, Mayr M, Dietrich H, Wick G, $\mathrm{Xu}$ Q: Reduced neointima hyperplasia of vein bypass grafts in intercellular adhesion molecule-1-deficient mice. Circ Res 2000;86 434-440.
60 Wang K, Zhou Z, Zhou X, Tarakji K, Topol EJ, Lincoff AM: Prevention of intimal hyperplasia with recombinant soluble P-selectin glycoprotein ligand-immunoglobulin in the porcine coronary artery balloon injury model. J Am Coll Cardiol 2001;38:577-582.

61 Isoda K, Nishikawa K, Kamezawa Y, Yoshida M, Kusuhara M, Moroi M, Tada N, Ohsuzu F: Osteopontin plays an important role in the development of medial thickening and neointimal formation. Circ Res 2002;91:77-82.

$62 \mathrm{Hu}$ Y, Baker AH, Zou Y, Newby AC, Xu Q: Local gene transfer of tissue inhibitor of metalloproteinase-2 influences vein graft remodeling in a mouse model. Arterioscler Thromb Vasc Biol 2001;21:1275-1280.

63 Diskin CJ, Stokes TJ, Dansby LM, Radcliff L, Carter TB: Understanding the pathophysiology of hemodialysis access problems as a prelude to developing innovative therapies. Nat Clin Pract Nephrol 2008;4:628-638.

64 Unnikrishnan S, Huynh TN, Brott BC, Ito Y, Cheng $\mathrm{CH}$, Shih AM, Allon M, Anayiotos AS: Turbulent flow evaluation of the venous needle during hemodialysis. J Biomech Eng 2005; 127:1141-1146.

65 Ortega JM, Small Wt, Wilson TS, Benett WJ, Loge JM, Maitland DJ: A shape memory polymer dialysis needle adapter for the reduction of hemodynamic stress within arteriovenous grafts. IEEE Trans Biomed Eng 2007;54:1722-1724.

66 Huynh TN, Chacko BK, Teng X, Brott BC, Allon M, Kelpke SS, Thompson JA, Patel RP, Anayiotos AS: Effects of venous needle turbulence during ex vivo hemodialysis on endothelial morphology and nitric oxide formation. J Biomech 2007;40:2158-2166.

-67 Kroll MH, Hellums JD, Mclntire LV, Schafer AI, Moake JL: Platelets and shear stress. Blood 1996;88:1525-1541.

68 Cho JS, Ouriel K, DeWeese JA, Green RM, Chen GY, Stoughton J: Thrombus formation on polytetrafluoroethylene surfaces: the importance of von Willebrand factor. Cardiovascular Surgery 1995;3:645-651. 